\title{
Technical efficiency of vegetable farmers in Peri-Urban Ghana influence and effects of resource inequalities
}

\author{
Samuel Twumasi Amoah ${ }^{1,}$, ${ }^{*}$ Irene Akobour Debrah ${ }^{2}$, Razak Abubakari ${ }^{3}$ \\ ${ }^{1}$ Department of Environment and Resource Studies, University for Development Studies, WA, Ghana \\ ${ }^{2}$ Faculty of Education, University for Development Studies, WA, Ghana \\ ${ }^{3}$ School of Business and Law, University for Development Studies, WA, Ghana
}

\section{Email address:}

atwumasi@uds.edu.gh (S. T. Amoah)

\section{To cite this article:}

Samuel Twumasi Amoah, Irene Akobour Debrah, Razak Abubakari. Technical Efficiency of Vegetable Farmers in Peri-Urban Ghana Influence and Effects of Resource Inequalities. American Journal of Agriculture and Forestry. Vol. 2, No. 3, 2014, pp. $79-87$.

doi: 10.11648/j.ajaf.20140203.14

\begin{abstract}
In Ghana, statistics indicate that women account for about $70 \%$ of total food production and are the most important actors in the food chain which begins from the farm production, market and intra household distribution of food. They play a lead role in post-harvest activities such as shelling of grains, storage, processing and marketing. They are also becoming increasingly visible in farm tasks which traditionally have been designated as male preserve. Despite the increasing central role of women in food production, they have much more limited access to resources than their male counterparts especially in the areas of education, land, agricultural extension services and access to credit, all of which combine to restrain their ability to increase productivity. This study was therefore undertaken toexamine the technical efficiency of male and female vegetable farmers in the Kumasi Metropolis using the stochastic production frontier model. Female vegetable farmers were found to be producing at high levels of inefficiency. The predicted efficiencies differed substantially from between 2 and 85 percent, with mean efficiency of 24 percent. The low mean efficiency index is an indication of inefficiencies in resource use. Also, female headed farms recorded a mean technical efficiency of 16.5 percent with a range between 2 and 66 percent. The male headed farms, on the other hand, showed a mean technical efficiency of 30.8 percent, and a range between 2 and 85 percent. The results imply that on the average, female vegetable farmers were relatively technically inefficient than their male counterparts. The paper concludes that since women farmers contribute immensely of domestic food supply in Ghana, it is important that efforts be made to build their capacity to produce efficiently.
\end{abstract}

Keywords: Inefficiency, Stochastic Frontier Model,Peri-Urban, Vegetable, Farmers

\section{Introduction}

In Ghana, agriculture is probably, the most important national asset since the economy and majority of the population is dependent on it. This sector is the largest in the economy in terms of its contribution to the Gross Domestic Product (GDP) and employment. The sector accounted for $34.5 \%$ of GDP in 2009. With increased demand for agricultural inputs such as land and water resources, in a framework of increasing environmental concerns, it has become important that measures are taken not only to improve productivity levels of farmers but also to do so in a manner that can sustain the environment. Increasing the productivity of farmers will require improvements in production technology through research and development, as well as a strong extension base that can offer a robust platform for technology transfer and monitoring. This is to ensure adoption and feedback to research stations for continuous evaluation and improvements [16].

Agriculture's contribution to the overall economic growth and development of the country has been, and continues to be, very significant, notwithstanding Ghana's oil find [16]. It is therefore important that for Ghana to achieve Millennium Development Goal One (MDG1) which aims at eradicating poverty and hunger, there is the need to put pragmatic measures in place to implement appropriate policies and projects. These should aim at promoting and substantially increasing agricultural productivity so that the country can attain food selfsufficiency. This requires that all sub-sectors in the agricultural sector are given special attention. This is 
because any changes or developments made in the any of the sub-sectors can have a prominent knock-on-effect on the entire agriculture sector and the economy in general. Unfortunately, there seem to be over concentration on the traditional export crops such as cocoa, and coffee to the neglect of the other non- traditional crops banana, pineapple among others. However, low producer prices for the traditional crops on the international market, persistent threats from climate change and issues of food insecurity have brought to the fore the need to pay much attention to the less developed sub-sectors of the agricultural sector. One important sub-sector that is worthy of mention in this direction is the vegetable sub-sector.

The worldwide production of vegetables has doubled over the past quarter century and the value of global trade in vegetables now exceeds that of cereals. The vegetable sector is the source of livelihood for millions of growers and thousands of traders and processors. As of 2007, a total volume of over 880 million tonnes of vegetables were being produced globally and it was expected to reach the 1.2 billion tonnes by 2015 [16]. Vegetable is an important cash crop, as well as staple food consumed by majority of Ghanaians in both rural and urban communities across the country. The vegetable sector has seen lots of fluctuations at the production levels. For instance, in 2010, 410,794 tonnes of vegetables were produced but it reduced to 329,019 tonnes in 2011, representing a drop of 2,417 tonnes. This correspondingly affected total revenue accruing to the sub-sector. In 2010, total revenue from the sub-sector was $\mathrm{GH} \square 102,091,000(40,371,477.71$ USD) but in 2011 total revenue fell to GH $\square 101,617,000$ (40,184,036.21 USD)[16] This was due to the liberalization of the domestic market in 1992 in the course of the structural adjustment programmes which started in 1983 and led to the invasion of the local vegetables market by foreign imports from neighbouring countries like Burkina Faso, Mali and Niger [14]. The importation of vegetables is ousting the local vegetable producers from the domestic market and that is making many local vegetables farmers lose their source of livelihood. Besides the huge importation of vegetables, local vegetable farmers are not technically efficient enough to meet the demand of the market. It is therefore, not surprising that the 800,000 Ghanaian vegetable farmers in the country could not satisfy the vegetable demand in 2011 [25]. The increasing volume of imported vegetables implies increasing expenditure on the commodity.

Factors such as climate change and poorly organized markets for local vegetables have been implicated for the low output which may account for the significantly higher imports experienced in recent years. The current widespread practice of traditional vegetable cultivation, which is dominated by women, is perceived to be the key reason for the deficit. The vegetable industry in Ghana can be regarded as having three distinct components: Commercial/Market gardening areas sited around the principal cities such as Accra, Kumasi, Takoradi and Tamale; a form of truck farming in which vegetables are produced in rural areas from where they are purchased by contractors or middlemen and transported by road to the cities and small domestic or backyard gardening [7]. The importance of vegetables cannot be over emphasized. Almost all vegetables are low in fat and calories, none has cholesterol, and many of them are great sources of fiber. The high levels of fiber in vegetables keep the digestive system healthier, allowing the individual to avoid issues with constipation. Since vegetables are low in calories, it enables individuals to eat lots of vegetables without consuming excess energy [18]. The presence of many vitamins and other substance in vegetables provide nutrients to the body. Vegetables provide essential amino acids that the body needs to survive.

Vegetable farming activities in tropical Africa has always been dominated by women who grow a substantial amount of the staple foods, yet, they have much less access to knowledge, technology, credit and land than their male counterpart [24]. Generally, resource constrained women farmers on the African continent are believed to produce up to $70-80 \%$ of the domestic food supply in most subSaharan African societies [17]. On average, they also provide $46 \%$ of the agricultural labour. This notwithstanding, women's yields are too low by Green Revolution standards (3 to 4 tonnes per hectare). Again, women's yields are much lower than men's yields in societies where a comparison can be made (ibid). According to Quisumbing [31]., gender differences in productivity goes beyond management styles to include differences in the intensity of use of productive inputs such as fertilizer, manure, labour, credit, extension training, and education. It has also been established by research that The Structural Adjustment Programme (SAP) embarked upon by Ghana further worsened the plight of women in agriculture who are already disproportionately burdened. The SAP was accompanied by the removal of subsidies from agricultural inputs and rather introduced trade liberalization measures which eventually resulted in the importation of vegetables that were hitherto being produced locally [29]. This situation had a telling effect on the local economy particularly local vegetable producers, especially women farmers [22]. It is for this reason that estimates by Udry [36]opines that if productive inputs such as fertilizer, manure and credit could only be reallocated within the African household, food crop production could increase in the range of $10-20 \%$. For anyone interested in women's welfare, the cultivation of African traditional vegetables offer an important entry point. Vegetable cultivation provides an important economic pillar upon which women's livelihood is supported. This is because the production, handling and marketing are mostly done by women [27].

Vegetable farming which is mostly done in urban and peri-urban areas in Ghana has unfortunately not received the appropriate public and institutional support despite its significant contributions to urban food security, poverty alleviation, women empowerment and improved human nutrition through the provision of balanced diets. Ghana 
has a high potential and positive comparative advantage for vegetable production but considerable evidence suggests that serious bottlenecks exist in the functioning of the production system. Anecdotal evidence and inquiry suggest that, a number of factors are responsible for the low vegetable production at the household level. The question then arises as to how efficient farmers are using or combining the available scarce resources at their disposal to produce the maximum desired output.

The vegetable production sector in Ghana is largely not properly institutionalized, not properly organized and inefficient [25]. The sector is plagued with Post-harvest problems. It is also fragile to harsh weather conditions at the retail level and this often results in high losses, which sometimes serves as disincentive and discourages producers, marketers and consumers [25]. The problems are acute for dry season vegetable crops. The depth of research and knowledge on the level of production efficiency and on ways to improve the efficiency of vegetable production in Ghana is limited. The literature search on the use of stochastic frontier approach to determine the technical efficiency of vegetable farmers yielded very scanty results. While it is obvious that the vegetable production sector in Ghana is not efficient, knowledge about the exact level of is quite blurred. It is also not clear what the impediments, particularly the extent of their impact to efficient vegetable production are. In order to adopt measures in solving the problem of inefficiency in the vegetable production sector, there is need to obtain more specific evidence as to the magnitude of inefficiency. These are key issues central to this study and whose investigation can be useful for the formulation of policies to strengthen and improve the efficiency of vegetable production system

The study is organized in four main parts. After the introduction, the next section outlines the methodology adopted for the study, which draws on the stochastic frontier production function model and the last two sections are devoted to the results and policy implication of the study.

\section{Materials and Methods}

\subsection{Study Area}

Kumasi is located in the transitional forest zone and is about $270 \mathrm{~km}$ north of the national capital, Accra. It is between latitude $6.35^{\circ}-6.40^{\circ}$ and longitude $1.30^{\circ} \mathrm{C}-$ $1.35^{\circ} \mathrm{C}$, an elevation which ranges between $250-300$ metres above sea level with an area of about 254 square kilometres. The unique centrality of the city as a traversing point from all parts of the country makes it a special place for many to migrate to. The Metropolis falls within the wet sub-equatorial type. The average minimum temperature is about $21.5^{\circ} \mathrm{C}$ and a maximum average temperature of $30.70 \mathrm{c}$. The average humidity is about 84.16 per cent at 0900 GMT and 60 per cent at 1500 GMT. The moderate temperature and humidity and the double maxima rainfall regime $(214.3 \mathrm{~mm}$ in June and $165.2 \mathrm{~mm}$ in September) have a direct effect on agricultural activity.

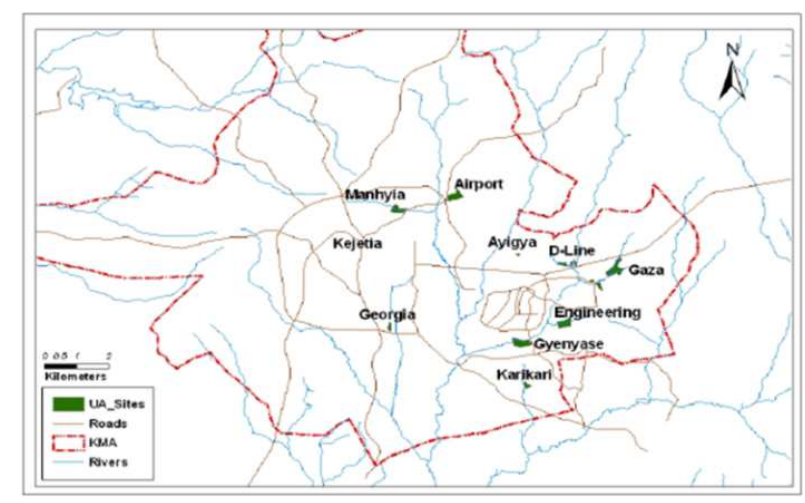

Figure 1. Vegetable Production Sites in Kumasi (Adams Abdulai, [2])

The major soil type of the metropolis is the Forest Ochrosol. The detailed soil associations are the following: Kumasi - Offin Compound Association; Bomso - Offin Compound Association; Nhyanao - Tinkong Association; Bomso - Suko Simple Association; Bekwai - Oda Compound Association and Bekwai - Akumadan - Oda Compound Association. It is a very rich type of soil that has made it possible for a lot of foodstuff (vegetables, plantain, cassava etc) to be grown in the periphery.Agriculture in the metropolis has seen a dramatic change in the last two decades due to rapid urbanization. The demand for residential, industrial and commercial land uses has become much greater than that of agricultural land use. Following this, it has been estimated that about $80 \%$ of the arable lands have been displaced by the construction of houses and other physical infrastructure.It has been estimated that the metropolis has 12,000 hectares of irrigable lands consisting of swampy and marshy areas (Metro.Agriculture Directorate). Agricultural land use in the metropolis has been consigned to crop farming in the peri-urban communities (eg. Dichemso, Takyiman, Parkoso, Apeadu, Kokoben etc) and along the banks and valleys of rivers/streams. Some of the common vegetables that are commonly cultivated by the farmers include,Cabbage, Carrots, Green pepper, Lettuce, Garden eggs, Pepper, Okra and Shallots among others. The main locations for vegetable cultivation are Gyinyasi, KNUST, Manhyia, Kakaro, Georgia and Asokore Mampong. Besides vegetable production, the cultivation of food crops like yam, cocoyam, plantain, cereals, legumes and fruits take place concurrently.

\subsection{Stochastic Frontier Production Model}

The Stochastic Production Frontier (SPF) is used to study technical efficiency of production. The model was originally developed by Aigner, Lovell, and Schmidt [4] The production and cost analysis in the stochastic frontier framework involves two steps. With the first step, the frontier model is estimated, usually by maximum likelihood while in the second, the model so estimated is used to determine measures of inefficiency or efficiency. The technical relationship between 
inputs and outputs of a production process is described by a production function which establishes the maximum level of output attainable from a given measure of input when using the stochastic frontier approach. This is the reason why it is called the production frontier.

The SPF has been more popular because it can handle statistical noise, resulting in more accurate specification. A more complete specification is essential for accurate efficiency measures since the estimated frontier is conditional on the functional form. In the writings of Bravo-Ureta and Reiger [8], modelling production functions using the stochastic frontier analysis is in consonance with production theory. According to Kumbhakar and Lovell [23], there are two main objectives in stochastic frontier analysis. First, it serves as a benchmark against which to estimate technical efficiency of producers. Second, it incorporates exogenous variables that are neither input nor output in the production process, but which nonetheless affect producer performance. Although, the stochastic frontier method has the foregoing strengths; it has been criticized on the grounds that there is no a priori justification for the selection of any particular distributional form for the technical inefficiency term, $u i$. The stochastic frontier analysis concerns the estimation of frontiers, which envelop data, rather than with functions which intersect data [23]. The frontier production shows the maximum output obtainable from given quantities of inputs representing maximum efficiency. Technical inefficiency is measured from the frontier level. The stochastic frontier production function specification enables the separation of output shortfalls due to technical inefficiency from those caused by random disturbances.

The stochastic frontier production function model used by Parikh and Shah [30] begins by considering a stochastic production function with a multiplicative disturbance term of the form:

$$
y=f(x ; \beta) e^{\varepsilon}
$$

where:

$y$ is the quantity of agricultural output

$x$ is a vector of input quantities

$\beta$ is a vector of parameters and

$e$ is a constant/exponent

$\varepsilon$ is a stochastic disturbance term consisting of two independent elements $u$ and $v$, with

$$
\varepsilon=v-u
$$

Equation (1) can thus be re-written as:

$$
y=f(x ; \beta) \cdot \exp (v-u)
$$

The measure of technical efficiency for each farm can be calculated using the formula:

$$
T E=\exp \cdot[E\{u / \varepsilon\}]
$$

And $u$ in equation (4) is defined as:

$$
u=f\left(Z_{b} ; \delta\right)
$$

Where $Z_{b}$ is a vector of farmer-specific factors and $\delta$ is a vector of parameters.

The symmetric component, $v$, accounts for random variation in output due to factors outside the farmer's control, such as weather and diseases. It is assumed to be independently and identically distributed as $N \sim\left(0, \sigma_{v}^{2}\right)$. A one-sided component $u \geq 0$ reflects technical inefficiency relative to the stochastic frontier. The advantage of this model is that it allows for simultaneous estimation of the production part of the frontier model and the individual technical efficiency/inefficiency component.

\subsection{Data Collection}

This cross-sectional survey utilized data from vegetable producers in the Kumasi Metropolitan Area (KMA). Five peri-urban communities were purposively selected based on the concentration of vegetable producers. These villages are Ayigya, Gyenyaase, Karikari, Georgia and D-Line. At least 50 farmers were randomly selected from each of the vegetable producing communities. Respondents in the survey included farmers who grow a particular type of vegetable on a particular piece of land and farmers who grow two types of vegetables on the same piece of land at different times of the year. Farmers were selected on the basis of gender, input and output per head. A total of 250 farmers were interviewed. At least, 6 out of 10 respondents were men. Additionally, five different focus group discussions were held, one in each of the five communities selected for the study. Each focus group had seven participants of which four were males and three were females with average age of 33 and 30 respectively. With respect to educational qualification, on the average highest level was Junior High School. In all, more males took part in the study than females and this is explained by the land tenure arrangement in the study area which favored males. Some of the issues that were probed included access to land and its security, availability of fertilizers, loans, farm inputs and improved seeds among others. The discussions were done in the local language and later transcribed. The purpose of the FGD was to stamp or otherwise, the responses obtained from the questionnaire interview. This approach is deemed appropriate when the object of the research is to explore altitudes or reactions of a group or community in response to some commonly experienced aspects of their environment [37] Through such interactive discourse, participants are able to offer insights on the perspective of the community, revealing clues to the social contexts that shape their opinions ([33]; [34]).

\section{Results and Discussions}

\subsection{Results}

Our hypotheses were stated in null terms. The first null hypothesis stipulates that there is no technical inefficiency effect in the production function, see Table 1. This null 
hypothesis is rejected for vegetable producers in the study area. Thus, it can be concluded that the explanatory variables in the efficiency model do contribute significantly to the explanation of the technical inefficiency effects for the vegetable producers. As pointed out by Coelli and Battese [11], if a null hypothesis includes $\gamma=0$, then the statistic has asymptotically a mixed Chi-squared distribution, since by its definition $\gamma$ has to be non-negative.In the second null hypothesis, we state that the variables included in the inefficiency effect model have no effect on the level of technical inefficiency. This null hypothesis is also rejected for vegetable producers, showing that the joint effect of these variables on technical inefficiency is statistically significant. A standard $t$-test for independent samples was used to test for statistical significance of the difference in gross revenue of male vegetable farmers and their female counterparts in the KMA. The mean difference for the gross revenue of male vegetable farmers and their female counterparts is significantly different from zero. The null hypothesis of equality of means is rejected under variance assumption $(\operatorname{Pr}(T<t)=0.009)$. The gender index is negatively associated with the level of technical inefficiency at the $1 \%$ level of significance. This implies that men are more productive than the women in the area so far as vegetable production is concerned.

Table 1. Hypothesis tests

\begin{tabular}{lccc}
\hline Null Hypotheses & Likelihood & $\chi^{2}$ statistic & $\chi_{\mathbf{0}}^{2}$ \\
\hline $\begin{array}{l}\text { 1. } \mathrm{H}_{0}: \gamma=0 \\
\text { Decision: Reject the null; no technical inefficiency in the model }\end{array}$ \\
$\begin{array}{llll}\text { 2. } H_{0}: \delta_{1}+\ldots+\delta_{6}=0 & -365.13 & 113.4 & 11.07 \\
\text { Decision: Reject the null; variables included in the inefficiency effect } \\
\text { model have no effect on the level of technical inefficiency }\end{array}$ \\
\hline
\end{tabular}

*The critical values for the test of null hypothesis was obtained from table 1 of Kodde and Palm [20]

\subsubsection{Stochastic Production Frontier Model Approximation}

The utmost likelihood estimates of the model parameters are computed using the frontier models routine of the Statistical package STATA with a Cobb-Douglas functional form. The real investigations for the occurrence of inefficiency were calculated by estimating the stochastic frontier production function and conducting a likelihood-ratio test assuming the null hypothesis of no technical inefficiency. This test statistic is computed automatically when the frontier model is estimated using STATA. Table 2 is the presentation of the parameters and related statistical test obtained from the stochastic frontier production function analysis. The estimated coefficient for farm size, labour, fertilizer and seeds are positive and statistically significant at least at the 5\% level. A $1 \%$ increase in expenditure on fertilizer, and seed will lead to about $0.95 \%$ and $1.87 \%$ increase in gross revenue respectively (all things being equal).
Table 2. Maximum Likelihood Estimates of The StochasticProduction Function

\begin{tabular}{|c|c|c|c|}
\hline Variable & Coefficient & $\begin{array}{l}\text { Standard } \\
\text { Error }\end{array}$ & $\begin{array}{l}\text { T- } \\
\text { statistic }\end{array}$ \\
\hline \multicolumn{4}{|l|}{ Production part } \\
\hline Constant & $14.360^{*}$ & 7.66 & 0.061 \\
\hline Farm Size & $0.667^{* *}$ & 0.303 & 0.026 \\
\hline Labour & $0.148^{* *}$ & 0.069 & 0.012 \\
\hline Herbicides (cedis) & 0.881 & 0.634 & 0.164 \\
\hline Fertilizer (cedis) & $0.950^{* *}$ & 0.473 & 0.037 \\
\hline Seed (cedis) & $1.875^{* * *}$ & 0.536 & 0.008 \\
\hline \multicolumn{4}{|l|}{ Inefficiency effect $(\mu)$} \\
\hline Constant & -0.654 & 0.982 & 0.666 \\
\hline $\begin{array}{l}\text { Gender of the farmer } \\
\text { (male }=1,0 \text { otherwise) }\end{array}$ & $-0.011^{* * *}$ & 0.003 & 3.667 \\
\hline Age (years) & $0.413^{* * *}$ & 0.015 & 27.533 \\
\hline Education (years) & -0.517 & 1.223 & 0.131 \\
\hline Farming experience (years) & $-0.114^{* * *}$ & 0.012 & -9.500 \\
\hline Extension contacts & -0.948 & 0.612 & -1.549 \\
\hline $\begin{array}{l}\text { Credit (Access=1, } 0 \\
\text { otherwise) }\end{array}$ & $-2.400^{* * *}$ & 0.166 & -14.458 \\
\hline $\begin{array}{l}\text { Variety of vegetables seed } \\
\text { (improved }=1,0 \text { otherwise) }\end{array}$ & $-1.056^{* * *}$ & 0.152 & -6.947 \\
\hline \multicolumn{4}{|l|}{ Model diagnostics } \\
\hline Likelihood ratio (1) & -162.50 & & \\
\hline Sigma square & 30.32 & & \\
\hline Gamma & 0.34 & & \\
\hline Prob $>$ Chi 2 & 0.008 & & \\
\hline Wald Chi2 (6) & 70 & & \\
\hline Wald Chi2 (4) & 113 & & \\
\hline Likelihood ratio (2) & -365.5 & & \\
\hline
\end{tabular}

$* * * * * *$ and $*$ represent statistical significance at the $0.01,0.05$ and 0.1 levels, respectively.Source: computed from survey data, 2012

Similar studies by Chinwuba and Odjuvwuederhie [10] found that expenditure on labour, fertilizer and seed yams, which constituted the material input variables shown by the frontier production function, positively affected revenue of farmers in Southeastern Nigeria [10]. Fertilizer is a major land augmenting input that increases yield per hectare by improving fertility of the soil. Our result also confirms the work of Weir [38] who found fertilizer to have a positive and significant impact on output. Abdulai and Huffman [3] found a negative relationship between the use of fertilizer and the level of profit inefficiency in the Northern region of Ghana. The estimated coefficient of herbicide though positive is not statistically significant even at the $10 \%$ level of significance. This implies that expenditure on herbicide will not lead to any significant increase in the gross revenue of vegetable producers in the area (Table 2).

\subsubsection{Efficiency Levels}

The sources of efficiency/inefficiency were examined using the estimated $\delta$ coefficients associated with the inefficiency effect. The inefficiency effects examined are those relating to age, gender, farming experience, education, access to credit, extension and seed variety. A negative sign on a parameter explaining inefficiencies means that the variable is improving technical efficiency, while for a positive sign, the reverse is true. As indicated in Table 2, the estimated coefficient on age was positive and statistically significant at the $1 \%$ level. This implies that 
farmers who had advanced in age were relatively less efficient in vegetable production. Since labour productivity decreases with age, younger farmers tend to be more productive than their older counterpart. The estimated coefficient on gender of the farmer $($ male $=1$, female $=0$ ) is negative and in consonance with a priori expectation. It is statistically significant at the $1 \%$ level. This implies that inefficiency is less on male plots than their female counterparts. The result is consistent with the findings of Due and Gladwin [13]. Also in relation to the findings of Akinwuni and Djato [5], they emphasized that the relative inefficiency of women vegetable farmers is not just because they are female but rather due to constraints that disproportionately affect them.

The estimated coefficient on years of experience is negative, conforming to a priori expectation, and it is statistically significant at the $1 \%$ level. The implication is that farmers with more experience in vegetable production were more efficient than the inexperienced ones in the area. The result is consistent with the work of Bravo-Ureta [9] who observed positive relationship between economic efficiency and experience in a study of dairy farms in New England. Vegetable farmers in the study area tend to use the knowledge acquired through experience on soil, and crop management in their farm operations.

The seed variety dummy was found to be negative and statistically significant at the $1 \%$ level. This implies that those farmers who adopted new vegetable technology in the form of improved vegetable seed were more efficient than those who used the traditional vegetable technology, a result consistent with that of Seyoum et al. [35] in Ethiopia. The estimated coefficient on education is not statistically significant but has the expected negative effect on inefficiency. The result, however, implies that the years of education tend to have no significant effect on the inefficiency levels of the vegetable farmers in the study area. The result is consistent with findings by Bravo-Ureta and Evenson [9] on peasant farmers in Paraguay. Seyoum et al., [35] demonstrated that education does not significantly affect the efficiency of farmers using traditional methods. Weir [38] also found a threshold effect that implies that at least four years of schooling are required to lead to significant effects on farm level technical efficiency, irrespective of gender.

The estimated coefficient on access to credit was negative, agreeing with a priori expectation, and statistically significant at the $1 \%$ level. This suggests that farmers who have access to credit tend to be more efficient in vegetable production. This finding is consistent with the work of Abdulai and Eberlin [1], which shows a positive association between credit and input use and farm productivity in Nicaragua. The availability of credit helps to finance the procurement of material inputs which have a positive effect on vegetable production.

The estimated coefficient on number of contact with extension officers was negative according to a priori expectation but is not statistically significant even at the $10 \%$ level. The result implies that more contact with extension officers tend to have no significant effect on the inefficiency levels of farmers in the study area. The result is not consistent with findings obtained by other researchers ([6]; [28]) because it is expected that more contact with extension workers will increase the farmer's likelihood of adopting improved vegetable technologies which will eventually increase the efficiency level of the vegetable farmer. The result is not surprising because the rate of adoption of land augmenting technologies such as improved seed and fertilizer is very low in the KMA. About $70 \%$ of the respondents use the traditional input. Thus, knowledge disseminated by extension officers to the vegetable farmers may not affect their output significantly, as the knowledge is on improved vegetable variety.

The inefficiency component of the disturbance term $(\mu)$ of the estimated frontier model is significantly different from zero $(p=0.008)$ indicating the presence of statistically significant inefficiency in the data. The likelihood ratio, sigma square and gamma parameters present results on the behavior of the error term outlined in the inefficiency model. The gamma measures the percentage variations in plot output due to technical inefficiency. If gamma is significantly different from zero it implies that there is technical inefficiency in vegetable production. The percentage variation in plot output due to technical inefficiency (gamma) is $34 \%$. The maximum likelihood estimates of the inputs parameters show the expected signs for all production inputs.

\subsubsection{Efficiency Indices among Vegetable Producers in the $K M A$}

Table 3 indicates that female vegetable farmers recorded a mean technical efficiency of 16.5 percent with a range between 2 and 66 percent and a standard deviation of 21.7 percent. The male vegetable farmers, on the other hand, showed a mean technical efficiency of 30.8 percent, a range between 2 and 85 percent and a standard deviation of 26.5 percent. The results imply that on the average, male vegetables producers are relatively technically efficient than their female counterparts, a result that is statistically significant at the $1 \%$ level.

Table 3. Distribution of Efficiency Indices amongVegetables Producers

\begin{tabular}{llll}
\hline Efficiency Index & Male \% & Female\% & Percent \\
\hline $0-10$ & 12 & 46 & 29 \\
$11-20$ & 34 & 26 & 30 \\
$21-30$ & 24 & 18 & 21 \\
$31-40$ & 6 & 4 & 5 \\
$41-50$ & 2 & 2 & 2 \\
$51-60$ & 10 & 2 & 6 \\
$61-70$ & 6 & 2 & 4 \\
$>70$ & 6 & 0 & 3 \\
N & 100 & 100 & 100 \\
Min & 2 & 2 & 2 \\
Max & 85 & 66 & 85 \\
Mean & 30.8 & 16.5 & 24.5 \\
STD & 26.5 & 21.7 & 23.3 \\
\hline
\end{tabular}


Given the specification of the Cobb-Douglas production function, the predicted efficiencies differ substantially among farmers, ranging between 2 and 85 percent, with mean efficiency of $24.5 \%$ and a standard deviation of $23.3 \%$. This low mean technical efficiency is an indication of high inefficiency in resource use. The distribution of the technical efficiency level in Table 3 shows that vegetable production on most plots is technically inefficient. For instance, the modal efficiency score group is 11-20 accounting for 30 percent of the total sample of vegetable farms, followed by 0-10 accounting for 29percent. Only 3 percent of vegetable farms have technical efficiency scores of more than 70 percent. The mean technical efficiency for the area is lower than that for most farmers in African countries whose mean technical efficiency range between 55 and 79 percent.

This finding is similar to the studies of Heshmati et al. [19] who obtained mean technical efficiency of 25 percent for the cereal farmers in rural Uganda and Weir et al. [39] who recorded a mean technical efficiency of 35 percent for cereal crop farmers in rural Ethiopia. The mean technical efficiency observed in the study area is also close to that of Mochebelele and Winter-Nelson [26] who obtained mean technical efficiency of 36 percent for rural households that send migrant workers from Lesotho to South African mines and 24 percent for households that do not send migrant labour.

In figure 2, the modal efficiency class for the women vegetable producers was $1-10$ and about 72 percent of the women's farms have technical efficiency levels below 21 percent. Their male counterparts on the other hand have their modal class as 11-20 and about 46 percent of the men's farms have technical efficiency levels below 21 percent. The result implies that technical efficiency is relatively higher on the men's vegetables farms than their female counterparts.

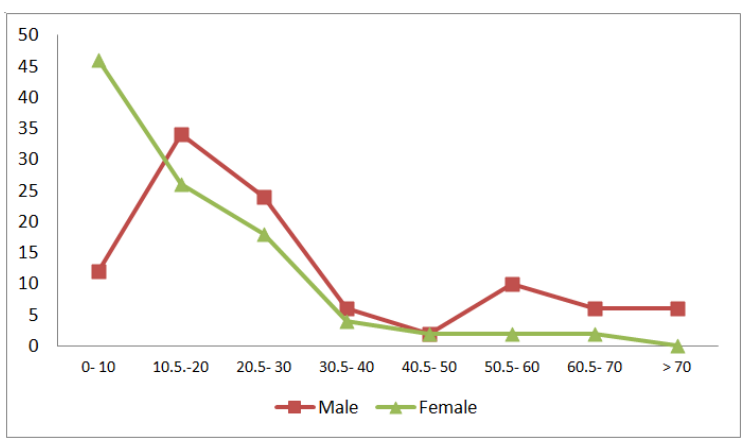

Figure 2. Distributions of Farm-specific Efficiencies in the Stochastic Production Frontier

\subsection{Discussions}

Vegetables are reputed to enrich household diets [21]. Adding to the debate, Dittoh [12] opines that vegetables add flavor to the food and also provide considerable protein, vitamins and minerals. He further asserts that most vegetables are low in starch content and are a good source of phyto- nutrients. They serve as roughage, which promotes digestion, and prevent constipation. We contend that if scarce production resources are efficiently allocated and utilized by vegetable farmers, not only will it provide employment, it will also improve the food self-sufficiency ratio of the country and eventually, Ghana will be a net exporter of vegetables. As intimated previously, the maximum likelihood approximation of the factor of the stochastic production function and inefficiency effects were calculated using the STATA software. This package estimates the two models simultaneously. To test for the functional form, the respective likelihood ratio tests were computed and their results compared with the critical values obtained from Kodde and Palm [20].

Seven factors were identified as sources of inefficiency/efficiency of the vegetable farmers. These were years of formal education, gender, access to credit, contact with extension officers, age, the farmer's experience in vegetables production and the seed variety planted by the farmer. The gender index was found to be a significant factor in reducing inefficiency in the area.

The seed variety index was found to be negative and statistically significant. This implies that those farmers who adopted new variety of vegetable seed were more efficient than those who used the traditional vegetables technology. The hypotheses tested show that first, all farmers are not operating at technically efficient level; secondly, expenditure on material inputs such as fertilizer and vegetable seed positively affect gross revenue; third, the variables included in the inefficiency model explain the observed variations; and fourth, there is relatively less observed inefficiency on the farms of male vegetable farmers compared to their female counterparts.

\section{Conclusion and Policy Direction}

The main purpose of this study was to examine the differences in technical efficiency among male and female vegetable farmers in the peri-urban areas of the Kumasi Metropolitan Area. Technical efficiency estimates were obtained using the Stochastic Efficiency Frontier Model. The results show that efficiency levels were significantly different across all production units. While some production units were efficient, there was some inefficiency in the production system. This suggests that a significant proportion of the error term in the production is explained by inefficiency effects. The frontier model used in this study was a static model. It must be emphasised at this point that our results only encapsulate the current levels of efficiency of the production units, which could change with time.

The results of the research show that there is more than enough opportunity for the vegetable farmers to increase production based on the existence of wide variations in the current level of productive efficiency. One of the variables that were significant in influencing production efficiency was age. Old age for example was associated with higher levels of inefficiency. It is therefore important that specific policies on vegetable production should be youth oriented. 
Similarly, increasing and improving access to credit and extension services should also be a priority of policy makers as financial support and extension services will enable farmers acquire the much needed input and new knowledge in the industry and this will eventually increase efficiency and productivity of farmers. Finally, it is recommended that gender-sensitive safety net programs that recognize women as vegetable producers will be worth an effort to reduce the inefficiency levels of vegetable producers in the KMA of Ghana. Vegetable farmers, especially the women, need to be better supported, if Ghana is to ever experience an increase in local vegetables production.

\section{References}

[1] Abdulai, A. and Eberlin E“Technical Efficiency During Economic Reform in Nicaragua: Evidence From Farm Household Survey Data". Economic Systems,2001(25):113125 .

[2] Abdulai, R. T, "Is land title registration the answer to insecure and uncertain property rights in sub-Saharan Africa?" RICS Research Paper Series, 2006, Volume 6(6), pp. $1-28$

[3] Abdulai, A., and Huffman, W,“Structural Adjustment and Economic Efficiency of Vegetables Farmers in Northern Ghana. Economic Development and Cultural Change, 2000(504-519)

[4] Aigner, D., Lovell, C.A., Knox, and Schmidt, P,"Formulation and estimation of Stochastic Frontier Production Function Models". Journal of econometrics, 1977(6) 21-37.

[5] Akinwumi, A., and Djato, K. K,"Relative Efficiency of Women as Farm Managers: Profit Function Analysis in Cote d'Ivoire": Agricultural Economics, 1997(16), 47-53.

[6] Ali, M., and Byerlee, D,"Economic Efficiency of Small Farmers in a Changing World: A survey of recent evidence. Journal of International Development, 1991, 13 (1): 1-27.

[7] Ayamba, I, "Backyard Crop Production in KMA". In: Kumasi Natural Resources Management Research Project (KNRMP)-Kumasi Urban Natural Resources Studies. R6799. 1999.

[8] Bravo-Ureta B.E. and Reiger L,"Dairy Farm Efficiency Measurement Using Stochastic Frontiers and Neoclassical Duality", American Journal of Agricultural Economics, 1991, 73 (2): 421-428.

[9] Bravo-Ureta, B. E. and Evenson, R. E,"Efficiency in Agricultural Production, the Case of Peasant Farmers in Eastern Paraguay". Agricultural Economics, 1994(10) 27-37.

[10] Chinwuba P. I. and Odjuvwuederhie E. I,"Determinants of Yam Production and Economic Efficiency of Smallholder Farmers in Southern Nigeria". Journal of Central European Agriculture, 2006, 7(2): 337-342.

[11] Coelli T. J and G. E .Battese,"Identification of Factors which Influence the Technical Efficiency of Indian Farmers"; Australian Journal of Agricultural Economics, 1996, Vol.
40, pp103-128.

[12] Dittoh, S, "The Economics of Dry Season Vegetable Production in Nigeria". Acta Horticulture, 1992, No. 296, pp. 257-264.

[13] Due, J.M. and Gladwin, C. H,"Impacts of Structural Adjustment Programme African Women Farmers and Female-headed Households". American Journal of Agricultural Economics 73 (1991): 1431-1439.

[14] FAO,Statistical Year Book, Food and Agriculture Organization (FAO), Rome. 2005

[15] FAO, Agricultural data FAOSTAT. Food and Agriculture Organization of the United Nations. Rome, Italy. 2006.

[16] FAO, Country Statistics: Ghana. Last accessed in 2011. Available

http://countrystat.org/gha/cont/pages/page/indicators/en

[17] Gladwin, C.H., McMillan, D, "Is a turnaround in Africa Possible Without Helping African women to Farm?" Economic Development and Cultural Change, 1989(37) 345-369.

[18] Hart, F.L. And Fisher, H.J,"Modern Food Analysis". Springer, Berlin,Germany. 1971, pp:371-373

[19] Heshmati, A. and Mulugeta, Y. Technical Efficiency of the Ugandan Matoke Farms, Applied Economic Letters, 1996(3) 491-494.

[20] Kodde, D.A, and Palm A.C. Wald, "Criteria for Jointly Testing Equality and Inequality Restrictions". Ecometrica, 1986 (54): 1243-1248.

[21] Komolafe, M.F., A.A. Adegbola, L.A. Are and T.I. Ashaye,Agric. Sci. West Africa Schools, Coll. Univ. Press Ltd. Ibadan, 1980 pp: 176-183.

[22] Kraus, J,“The struggle over structural adjustment in Ghana”. Africa Today, 1991, 38(4): 19-37.

[23] Kumbhakar, S. C. and Lovell, C. A. K, "Stochastic Frontier Analysis". Cambridge University Press, Cambridge. 2000.

[24] Minia, Z,"Climate Scenarios Developed for Climate Change Impact Assessment inGhana", Report prepared for the Environmental Protection agency under the Netherland. Climate Change Studies Assistance Programme (NCCSAP) Phase 2, Part 1, Accra. 2004.

[25] MoFA, “Agriculture in Ghana: Facts and Figures”. Ministry of Food and Agriculture, Accra. 2011.

[26] Mochebelele, M.T. and Winter-Nelson, A"Migrant Labour and Farm Technical Efficiency in Lesotho", World Development, 2000, 28 (1): 143-153.

[27] Nekesa P, \&Meso B,"Traditional African vegetables in Kenya: production, marketing and utilization" In: Traditional African Vegetables. Promoting the conservation and use of underutilized and neglected crops. 16. Guarino $\mathrm{L}$ editor. Proceedings of the IPGRI International workshop on genetic Resources of Traditional Vegetables in Africa: Conservation and Use, 29-31 August 1995, ICRAF-HQ, Nairobi, Kenya. Institute of Plant Genetic and Crop Plant Research, Gatersleben International Plant Genetic Resources Institute, Rome, Italy, 1997, pp.98-103. 
[28] Owens, T., Hoddinott, J. and Kinsey, B,"The Impact of Agricultural Extension on Farm Production in Resettlement Areas of Zimbabwe". CSAE WPS/2001-6, Centre for the study African Economics, University of Oxford. 2001.

[29] Owusu-Sekyere et al.,"Gender, Resource Use and Technical Efficiency Among Rice Farmers In The Ashanti Region Ghana". Journal of Agricultural Economics and Development, 2013, Vol. 2(3), pp. 102-110,

[30] Parikh, A., Ali, F., and Shah, M.K "Measurement of Economic Efficiencyin Pakistani Agriculture, American Journal Agricultural Economics, 1995, 77 (8): 675-685.

[31] Quisumbing, A. R,"Male-Female Differences in Agricultural Productivity: Methodological Issues and Empirical Evidence". Economic Development and Cultural Change, 1996, (24): 1579-96.

[32] Rahman S, "Profit Efficiency among Blanglandesh Vegetables Farmers”. Food Policy, 2003(2)8: 483-503.

[33] Scammell, M.L. \& Dearry, A,“Advancing the CommunityDriven Research Agenda in N.Lo.E.H, Research Triangle Park", North Carolina. 1997.

[34] Scammell, K.M., Senier, L., Darrah-Okike, J., Brown, P. \&
Santos, S,"Tangible Evidence, Trust And Power: Public Perceptions Of Community Environmental Health Studies". Social Science \& Medicine, 2009, 68(1):143-153, 6 Nov

[35] Seyoum, E. T., Battese, G.E. and Fleming, E. M,“Technical Efficiency and Productivity of Maize Producers in Eastern Ethiopia: A study of farmers within and outside the Sasakawa- Global 2000 Project. Agricultural Economics", 1998, 19: 341-348

[36] Udry, C. Gender, "Agricultural Production, and the Theory of the Household". Journal of Political Economy, 1996, (104): 1010-1046.

[37] Ulin, P. R., Robinson, E. T., \& Tolley, E. E, “Qualitative methods in public health: A field guide for applied research". San Francisco, CA: Jossey-Bass, 2005: Pp. 139-174.

[38] Weir, S, "The effects of Education on Farmer Productivity in Rural Ethiopia”, Working Paper CSAE WPS99-7, Centre for the study of African Economics, University of Oxford, 1999.

[39] Weir, S. and Knight, J,"Education Externalities in Rural Ethiopia: Evidence from Average and Stochastic Frontier Production Functions", Working Paper CSAE WPS99-7, Centre for the study of African Economics, University of Oxford. 2000. 